\title{
Philosophical Reflections on Ubuntu in the Context of Cooperative Learning
}

\author{
Chingombe Shamiso Iline ${ }^{1} \&$ Higgs Phillip ${ }^{1}$ \\ ${ }^{1}$ University of Kwazulu Natal, South Africa \\ Correspondence: Chingombe Shamiso Iline, Great Zimbabwe University, Zimbabwe. E-mail: \\ schingombe21@gmail.com
}

Received: April 26, 2019

Accepted: May 14, 2019

Online Published: May 20, 2019

doi:10.5430/irhe.v4n2p10

URL: https://doi.org/10.5430/irhe.v4n2p10

\begin{abstract}
Learning institutions ought to be receptive to the desires of humanity by moulding students who are all-inclusive and inspired with a vibrant consideration and obligation of who they are in relation to their immediate and external environment. The study focused on philosophical reflections on ubuntu in the context of cooperative learning in higher education. A qualitative methodology was adopted. Interpretivism and the grounded theory were the paradigms used in this study. A grounded theory has the potential to generate new theories based on the data collected from participants. The sample comprised of two lecturers who were purposively selected for their expertise in teaching philosophy. Findings clarified that ubuntu creates a teamwork culture which inspires students to work collectively in order to achieve a common goal. Ubuntu collection of themes indicated that ubuntu is a philosophy. From the African point of view ubuntu is a set of beliefs that refers to the way people relate at individual and personal level, but at the core of ubuntu there is an element of humanity. Ubuntu can act as a weapon to cover the weaknesses of colleagues. As the weaknesses of family members or other learners is protected or shielded it helps to build confidence and trust among the learners. Findings also revealed that ubuntu brings coordination and direction with due respect of individual abilities and differences. It was also noted that ubuntu is the cement or the glue that unifies, interrelates or interconnects individuals in cooperative learning. On a negative note it was revealed that without ubuntu there is irrationality, chaos, disorder, selfishness and separation, where everything is scattered. As the grounded theory emphasised the generation of a new theory, a communalist enhanced theory was adopted. The communalist enhanced learning anchored on social interdependence which promotes task, behavioural and goal interdependence.
\end{abstract}

Keywords: ubuntu, cooperative learning, grounded theory, Nvivo data analysis, humanity, team work, African philosophy, solidarity, group accountability, communal interdependence

\section{Introduction}

Living in the 21st century is influencing the way human beings interact with their colleagues and learn together. Twenty-first century competencies bring to the fore initiatives to enhance creative connections through the engagement of good teamwork. Teamwork supersedes the traditional classes that involved students who work competitively to determine who is best or individualistically without caring for others' performance (Belmekki \& Kebiri, 2004:29). Thus, teamwork promotes cooperative learning which in turn promotes students' responsibility for their own learning as well as the learning of others (Chadha, 2013:50). Teamwork is achieved through cooperative learning which is sometimes referred to as co-learning, "[is] where students work in small groups to achieve a common goal" (Ormrod, 2008:437). Mthiyane (2014:140) suggests that getting learners to become actively engaged and responsible for their own learning in class community enhances creativity and innovativeness in the culture of learning. Class community is achieved through ubuntu, which is defined as a form of human engagement that allows for critical thinking, non-domination and optimal development of human relationships (Letseka, 2011). This paper reflects how ubuntu is linked to cooperative learning.

\section{Philosophical Reflections on Ubuntu in the Context of Cooperative Learning}

Our argument and submission in this paper is that CL can essentially be understood to have its origin in ubuntu philosophy. Higgs (2003:13) argues that the underlying concern of "ubuntu" acknowledges that to be humane is to affirm one's humanity by recognising the humanity of others. Thus, ubuntu can act as a source and well-spring of CL since ubuntu itself has unity and cooperation and working together (togetherness) as necessary aspects that constitute 
it. CL cannot exist without the support of ubuntu. Letseka (2012:748) argues that amongst scholars who subscribe to the philosophy of ubuntu, Mbiti's ideas seem also to help us in understanding the value and place of ubuntu in cooperative learning. Letseka (2012) further observes that Mbiti is credited for connecting African communities and the notion of community with his most cited maxim: "I am, because we are; and since we are, therefore I am". The deeper thrust and emphasis of this principle is togetherness and cooperation. Our togetherness, as human beings, is not by chance or accident but cooperation is a necessity and our substance. Cooperation is that which originally places us into existence and in it we exist.

Ubuntu, as togetherness or cooperation, teaches us that the success of the class is perpetuated by teamwork but not at the expense of the individual. Ubuntu therefore aims to eliminate the spirit of individualism perpetuated through such teachings as, 'Ini ndini, Iwe ndiwe' (I am, you are), which emphasize the individual separateness from other members of the community (Hapanyengwi-Chemhuru \& Makuvaza, 2014:3). Nicolson (2008:9) characterises and understands ubuntu as in essence cooperation or teamwork and he argues that from an African perspective, the group understands that it is important to produce work and to finish the task at hand rather than competing as individuals in a hundred meter race. The emphasis is on communal values which mean that, in African tradition, community decisions are by preference made by consensus rather than by an individual.

Higgs (2003:15) posits that the development of cooperative skills in younger people will play a crucial role in promoting and sustaining the sort of communal interdependence and concern with the welfare of others that is encouraged by 'ubuntu'. Consequently, individuals rely on others just as others also greatly rely on them. Through ubuntu CL approaches take advantage of heterogeneity in class by encouraging learners to learn from one another and from more and less knowledgeable peers (Akhtar, Perveen, Kiran, Rashid \& Satti, 2012:144). What it means is that ubuntu can inspire, permeate and radiate, as confirmed by Samkange and Samkange (1980:8), its nature of connectedness and togetherness into the essence of cooperative learning. Similarly, Mandova and Chingombe (2013:100) identify ubuntu as a fecund source offering assistance and foundation to social activities like CL, and they further argue that ubuntu is a social philosophy which embodies virtues that celebrate mutual social responsibility, mutual assistance, trust, sharing, unselfishness, self-reliance, caring and respect for others, among other ethical values. Thus, infused and radiated with ubuntu, CL students do not have a goal to learn only, but also have a goal to help others in their group learn (Petty, 2006:150).

Iyer (2013:2) shares his conceptualization and understanding of CL and argues thus: "This is unlike in a race where individuals strive to be in the first position. During CL activities, each member of a team is responsible not only for learning what is taught but also for helping team-mates learn, thus creating an atmosphere of achievement". For CL to achieve this important task and goal it has to employ and be intimately and deeply rooted in ubuntu since ubuntu has as its foundation or essence relationship based on and characterized by sympathy, empathy, generosity, sister and brotherliness and many other similar moral qualities. Accordingly, through ubuntu, pre-service students can engage in CL to assist their colleagues to achieve set goals. In support of this point, Msila (2009:312) argues thus: "Communal aspects of African philosophy, when infused in education, can help create a community of learners who glean from one another in an unselfish manner".

Without ubuntu there is no CL but individualism, which celebrates that if one member falls along the way no one turns to assist the fallen competitor. Instead, one can rejoice over the failure of the other individual as this increases one's chance to be in the first position. Individualism is thus not learning but taking advantage of each other. What is needed is CL which is achieved and accomplished through interpersonal relationships with the group members, and this is genuine learning. Hence Mandova and Chingombe (2013:101) observe and identify ubuntu as the better tool in order to promote cooperative learning, and they argue that the traditional Shona society celebrates cooperation and discourages individualism. Human beings adapt to the community life in which they rarely work alone but always tend to interact in a safe social medium which supplies them the necessary support to continue their life (Gubbad, 2010:13). In concurrence, Letseka and Venter (2004) assert that the individual cannot exist alone hence whatever happens to the individual happens to the whole group, and whatever happens to the whole group happens to the individual. This can only be achieved through ubuntu. Brame and Biel (2005:2), in support of CL through ubuntu, assert that the success of the group is hinged upon the efforts of individuals within the group. The small groups are essential because students are heard and are able to hear their peers, while in traditional classroom settings students may spend more time listening to what the instructor says.

The nature and character of CL essentially calls for ubuntu as its foundation since CL promotes non-racialism, non-sexism, non-discrimination, and respect for freedom, human rights promotion and dignity of people, inter-dependence and a deep-rootedness of a collective community (Johnson, 2015:4). CL is thus one moral 
disposition or quality of ubuntu. Uprooted from ubuntu, CL loses meaning and value. Through ubuntu, CL ceaselessly enhances communalism wherein pre-service students depend on each other as they promote teamwork and thus become actively engaged and responsible for their own learning in a class. Since community enhances creativity and innovativeness in the culture of learning (Mthiyane, 2014:140), students from different cultural settings are expected to work as a team in a CL situation. This creates good human relationships and increases human value, trust and dignity (Venter, 2004:151). In order for CL to achieve these significant qualities and goals, it ought to, of necessity, rely strongly on ubuntu. In actuality, CL ought to be an activity consolidating ubuntu principles.

In addition, CL needs ubuntu because, as students work cooperatively, they become open and available to others, affirm and respect others, and do not feel threatened by the strengths or abilities of others as they recognize that they belong to a greater whole (Johnson, 2015:4). Ubuntu is these essential and basic moral qualities needed by those students involved or engaged in cooperative learning. Without ubuntu these moral axioms are impossible to attain and this in turn makes CL empty; a lie, falsity and impossibility. With ubuntu, these students identify themselves with their colleagues, thus they will work tirelessly towards achieving a common goal since ubuntu tends to shed selfishness and egocentrism among learners (Msila, 2009:314) and, in theory, ubuntu ensures that no voice goes unheard (Nicolson, 2008:9).

Interconnectedness and working together constitute the centre and basis of ubuntu. Applied to CL, these ubuntu qualities can inspire students to feel that from such a perspective, it is important to observe that opinions of the group are at the core as illustrated by the Shona expression 'rume rimwe harikombi churu' (one man cannot surround an anthill), which means that it takes the effort of a group to do something meaningful (Mangena, 2012:10-11). In addition, Masowa and Mamvura (2017:34) submit that ubuntu values togetherness and oneness, and shuns individualism as reflected in the following Shona proverbs:

\section{Kuchera mbeva kukomberana (Digging after mice involves surrounding them).}

Kuturika denga remba kubatirana (To put a roof onto the walls of a hut needs joining hands).

Hapanyengwi-Chemhuru and Makuvaza (2014:8) also argue that ubuntu emphasises interconnectedness. Through ubuntu, students should thus work hand in glove for them to succeed in their learning endeavours, since whatever a person does must be for the benefit of the community to which he or she belongs, rather than seeing one as a secluded being (Bondai \& Kaputa, 2016:44). However, Nicolson (2008:9) also understands ubuntu as in essence community-oriented and he argues that the emphasis on communal values means that in African tradition, community decisions are by reference made by consensus rather than by an individual. This implies that in cooperative learning, a substantial offshoot of ubuntu, students are expected to promote teamwork to come up with a decision for the whole group.

Higgs (2003:14) argues that ubuntu in an African educational discourse is fundamentally concerned with service of the community and personal well-being which is directed at fostering humane people endowed with moral norms and virtues such as kindness, generosity, compassion, benevolence, courtesy and respect and concern for others. With all that has been said about ubuntu, students ought to be engaged in cooperative learning, an essential quality of ubuntu, since it highlights that a human being is a human being through the otherness of other human beings (Johnson, 2015:2). Consequently, communal aspects of African philosophy of ubuntu when infused in education can help create a community of learners who glean from one another in an unselfish manner (Msila, 2009:312). In concurrence, ubuntu mainstreaming in the education curricula ensures and guarantees peace, harmony, spirit of brotherhood, togetherness, respect, solidarity, teamwork, unity, reconciliation and hard work among other important values (Bondai \& Kaputa, 2016:40). The impression is that there is need for ubuntu in CL for peace, love and harmony among students.

Furthermore, since students should be devoted to tasks under study and are obliged to respect varied views from their colleagues, students must be well rooted, groomed and vested in ubuntu philosophy. Ubuntu is a philosophy that valorises being human and the interconnectedness of human beings (Hapanyengwi-Chemhuru \& Makuvaza, 2014:8). Accordingly, community becomes the ultimate interest of ubuntu, that for which individuals sacrifice even life. Thus, in a learning environment, students, through ubuntu, can sacrifice to get the same mark with colleagues who may not be doing well. This is so because ubuntu has a link with communal interdependence; it also has a link with the value of love, sympathy and tolerance (Letseka, 2012:748). Subsequently, ubuntu ensures that an individual should not be an entity existing and flourishing on its own, unconnected to any community. Msila (2009:314) contends that ubuntu is one of the cornerstones of democracy in an African context as it demands one to live for others. Individuals thus need to identify with others. To identify with each other is largely for people to identify themselves as members of 
the same group, that is, to conceive of themselves as 'we', for them to take pride or feel shame in the group's activities, as well as for them to engage in joint projects, co-ordinating their behaviour to realise shared ends (Metz 2011:538). Through cooperative learning, one can live for others by ensuring that they are committed to the progress of the group. Conversely, the absence of ubuntu leads to tension, conflicts, frustration and disintegration of basic human relationships and community, because ubuntu does not merely represent positive human qualities; it is the very human essence itself, which enables human beings to become abantu (humanised beings), creating harmonious relationships in the community and the world beyond (Bitzer, 2001:100). The African concept of personality as already highlighted is based on the idea that Africans are inherently predisposed to work collaboratively and demonstrate interdependence, empathy, selflessness, communalism and interconnectedness (Kufakunesu \& Dekeza, 2017:54).

\section{Methodology}

Research methodology is the overall approach to studying a topic and includes issues to think about such as the constraints, dilemmas and ethical choices within a research (Dawson, 2002:14). It is a way to systematically solve the research problem (Kothari \& Garg, 2014:6). Research methodology involves research paradigms, which are models or frameworks for observing and understanding both what we see and how we understand it (Babbie, 2007:32). A qualitative research design, which is the "logic that links data to be collected to the initial questions of the study" (Yin, 2011:76), was adopted. Qualitative researches rely on linguistic rather than numerical data and employ meaning-based rather than statistical forms of data analysis. Distinctive features of qualitative research emphasise the understanding of phenomena in detail. Fischer (2006:xvi) notes that qualitative research is a reflective, interpretive, descriptive and usually reflexive effort to describe and understand actual instances of human action and experiences from the perspective of participants who are living through a particular situation. This is often achieved through participant observation where the researcher becomes much more involved in the lives of the people being observed (Dawson, 2002). Paradigms define researchers' nature of inquiry in the three dimensions of ontology, epistemology and methodology (Blanche, Durrheim \& Painter, 2006:6). While ontology specifies the nature of reality, epistemology specifies the nature of the relationship between the researcher and what can be known, and methodology is how the researchers may go ahead studying what they believe can be known (Blanche, Durrheim \& Painter, 2006:6). This reflects that paradigms form a backbone for considering a given phenomenon, guiding the researcher through research activities. Paradigms are fundamental conceptions of how to do a research in a specific field with consequences on the levels of methodology and theory (Flick, 2014:540). Somekh and Lewin (2005:347) also define the word 'paradigm' as a term used to describe an approach to research, which provides a unifying framework for understanding of knowledge, truth, values and nature of being. Paradigms are therefore vital for accepting and deciding the appropriate methodology to use in the study.

The interpretive paradigm was the design used to focus this study which aimed to understand the use of CL in teacher education. As the study sought to understand the experiences of students and lecturers, it situated itself within an interpretive paradigm. The interpretive paradigm emphasizes the importance of examining the world from participants' point of view (Tracy, 2013:41). Interpretivism's main tenet is that reality can never be objectively observed from the outside, it must rather be observed from inside through the direct experience of people (Mack, 2010:8). The researcher takes an active role in getting closer to the participant's personal world. Interpretive paradigm is concerned with understanding what it is like from the perspective of participants. From an interpretive point of view, a researcher can clearly explain, describe or translate into a research report what is reproduced through communication, interaction and practice (Tracy, 2013:40). Cohen, Manion and Morrison (2000:28) recommend the interpretive paradigm for striving to understand and interpret the world in terms of its actors. Hennick, Hutter and Bailey (2011:15) applaud the interpretive approach for allowing the researcher to study things in their natural setting in an attempt to make sense of or interpret phenomena in terms of the meanings people bring to them. Hennick et al. (2011:19) acknowledge that the perspectives of the study participants reflect their subjective views of their social world, and researchers also bring their subjective influence to the research process, particularly during data collection and interpretation. This is brought about by the use of open-ended questions. These enable the various respondents to give their varied suggestions and views on a particular case under study.

Grounded theory is also one of the paradigms used in this research. Tavakoli (2012:247) defined grounded theory as a general methodology of analysis in qualitative research which seeks to build systematic theoretical statements inductively from coding and analysing data. In grounded theory, methods such as focus group discussions and interviews tend to be the preferred data collection methods along with comprehensive literature review which takes place throughout the data collection process (Dawson, 2007:20). To this effect, the research generated a theory based on the data collected. 


\section{Research Findings}

In response to the question that sought to find out individuals' understanding of ubuntu, collection of themes indicated that ubuntu is a philosophy, it refers to the elements of humanness and humanity, entails reasoning, truth telling, hospitality, humility and dignity. It is also a hub of love. To help visualize the emerging themes, a word cloud was generated from the coded texts on individuals' understandings of ubuntu. The resultant themes that emerged from the study findings are illustrated in the word cloud in Figure 1 below.

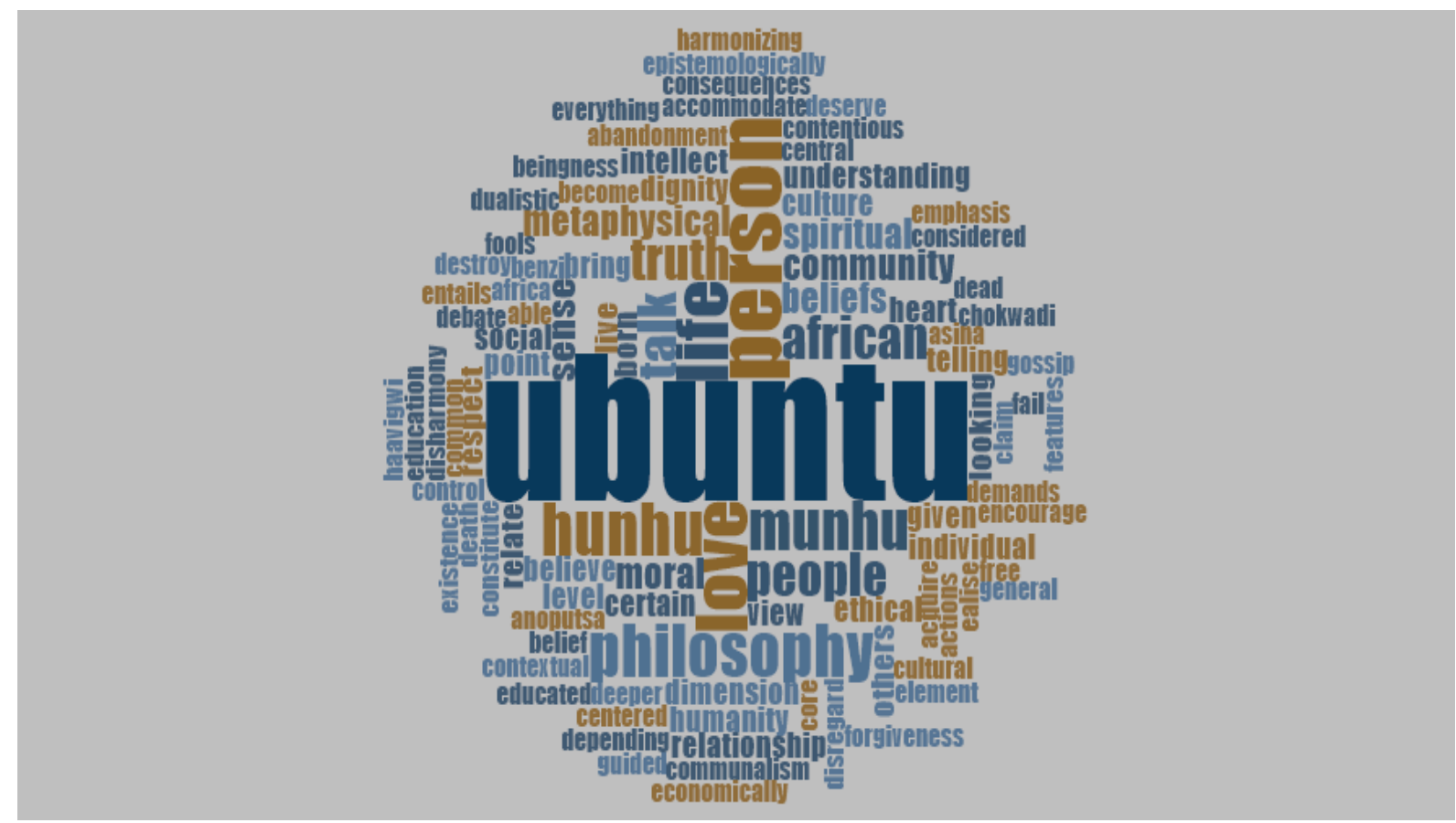

Figure 1. Field data on understandings of Ubuntu

One of the respondents indicated that:

Ubuntu can be understood as a philosophy and as a cultural belief depending on the notion of ubuntu required in education. From the African point of view ubuntu is a set of beliefs that refers to the way people relate at individual and personal level, but at the core of ubuntu there is an element of humanness and humanity. What is a person, what constitutes a person? So we will be looking at the ethical dimension of ubuntu then the metaphysical. When we refer to the ethical we are we looking at the moral. A person is someone who shares some moral traits that are common. But from a metaphysical point of view ubuntu can refer to the human ontology or existence of a person. In African sense life is dualistic; we have physical life and the spiritual life, that's why we talk of the living dead. So we say in ubuntu a person is more than the physical being. He has the intellect and the spiritual life and physical life. So in ubuntu we have the question of death where we say what dies is the physical being. But the spiritual being does not die. So in ubuntu we teach the whole person, sociological, psychological and the physical being. Now the intellect is usually not given more significance in ubuntu. Why? We have some Shona proverbs or sayings that accommodate and encourage us to respect a person in spite of his or her mental state. Munhu munhu haavigwi sembwa (A person is human, they cannot be buried like a dog). Ringava benzi (they may be mentally challenged) or a social misfit, yes, at general level we may disregard them as not a person but when we go deeper we believe that every person deserves some respect and dignity. So those are some of the features of ubuntu. Now from the Western dimension ubuntu is not considered as a philosophy. It is just taken as a set of beliefs without any direction because it cannot be verified. Because in philosophy we say philosophy must pass a certain test, there are certain tasks that we look for when we talk of philosophy. Not everything is philosophical, it entails reasoning which is not contextual but universal. But that is quite contentious because those who claim that ubuntu is not a philosophy are Westerners who believe or are 
guided by racial supremacy, so we may not delve in that debate of whether it is a philosophy or a set of beliefs. Ubuntu simply refers to the way people relate in a community. One cannot acquire ubuntu, he or she is born with it. You only need to realise it when you interact with others. On your own you cannot have it. Ubuntu is given by others. That is why we talk of educated fools. In Africa you don't learn about ubuntu but you realise it, and ubuntu is more worried about love which is the central trait of ubuntu. The hub of ubuntu is love, so from love is where all other tenets radiate. In ubuntu we talk of forgiveness, truth telling, hospitality, humility and dignity. The hub of ubuntu is love, without love in an African sense you do not qualify to be a person. That is why they say to preserve humanity is to love, so at times you are justified to tell lies in order to save life. Remember Marshall Munhumumwe's song, "pawazviona siya zviripo, ukazvitaura unoparadzanisa vakawanda" (when you see it do not speak of it, if you do you will cause divisions). Why they say so, kuchirungu zvinonzi (in the West they believe) only the truth will set you free. But telling truth in an African sense, if that truth may lead to negative results, unonzi hauna hunhu (is believed to show a lack of humanness). Kuva munhu kuchengetedza upenyu hwevanhu (to be human is to protect the lives of others) socially, economically and morally. That is why people hate gossiping, anoputsa chingava chokwadi chauri kutaura (it is destructive even when you are telling the truth) but you are not able to control the consequences of the gossip. So the moment your actions destroy social relations hauna hunhu (you do not have ubuntu). Kuva munhu kuvaka (being human is about building up), you bring people together, not bring disharmony among people. That's why we talk of communalism, harmonizing ndokuva munhu (is what being human is about).

The respondents had varied definitions of what CL is. One of the interviewees indicated that CL may entail learning that involves team participation where individuals have a contribution towards the learning process and achievement of goals in teaching and learning. It is working together, that is the teacher, student and educational stakeholders have a say towards the attainment of educational goals for the good of the individuals and the broader society. This means that the aims of education should address the needs of the self and others at a pragmatic level. It presupposes doing together or working together towards a common goal. It is a technique or a skill or a perspective which is a shift from an individualistic type of learning to a communalist type of learning. An individual is a community. It is a component found in ubuntu philosophy which is typically African; 'munhu munhu nevanhu'. No man is an island. We do it together and achieve together, and the end product does not belong to an individual but to us as a group. Divided we fall but united we stand.

A cluster analysis was used to identify the benefits of ubuntu in CL. A cluster analysis is an exploratory technique one can use with visual diagrams to provide a graphical presentation that gives an overview of the data from the participants. A cluster analysis on the benefits of ubuntu in CL is shown below. 


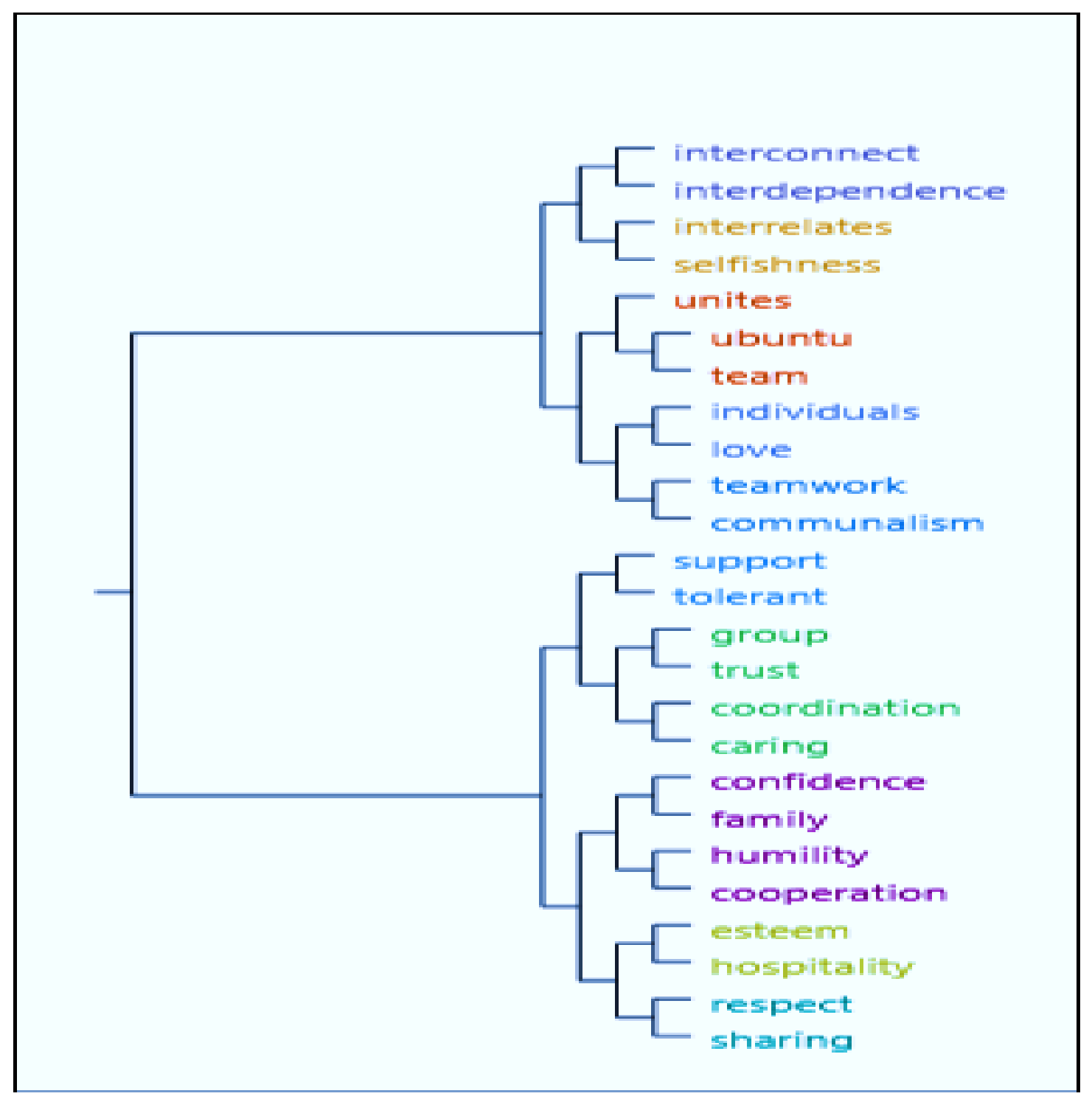

Figure 2. A cluster analysis showing field data on the benefits of ubuntu in CL

Ubuntu can act as a weapon to cover the weaknesses of colleagues, you may use ubuntu because we normally say I am because we are, since we are therefore I am. So the weaknesses of family members or other learners is protected or shielded so it helps build confidence and trust among the learners. Ubuntu also promotes the element of humility. Those who are gifted when they are in a group are expected not to boast about their self because they are in a group. They are supposed to be tolerant because they are in a group with other people so they lower down their identity so that they fit in the group. The moment you boast or show your ego you cannot expect cooperation from others, so it promotes humility and trust. How do you build trust in CL? The person who becomes your spokesperson does not represent the self, he or she represents the whole group so when we mandate a person with the right to be the leader of the group it is out of trust that he or she will deliver. It also boosts self confidence and self esteem among the learners. It also enables members concerned to develop the spirit of sharing and caring for others. When one makes mistakes in a team one doesn't feel betrayed when their colleagues use appropriate language or take you as one of them. When you are in a team you are like a family so you feel at home and loved. The element of caring is boosted, as well as hospitality. You are well received in CL because other group members take you as a part of them, like a body part. But a body on its own cannot achieve results unless there is coordination. CL in ubuntu brings coordination and direction with due respect of individual abilities and differences. So it helps people identify their 
different talents. We become conscious of other people's strengths and weaknesses, then we work towards an improvement and support of those gifts and do not shun them.

Ubuntu is identical to CL, without ubuntu there is no CL. Ubuntu is the cement or the glue that unifies, interrelates or interconnects individuals in CL. Ubuntu is the love and the good that marks the beginning, the process and the end of CL. Without ubuntu there is no reason to have CL. Hence without ubuntu there is irrationality, chaos, disorder, selfishness, and separation, everything is scattered. Ubuntu makes learning itself affordable and easy, since there is interdependedness in the sense that what is difficult for one is easy for the other. There is a spirit of communalism, rume rimwe harikombe churu (one man cannot surround an anthill). We have a holistic picture of what is to be learnt as all perspectives are given. Ubuntu is teamwork. Without ubuntu there is no team and no work will be done.

What makes a team is interdependence, good and love. Ubuntu makes the basis of teamwork. It dissolves differences among the individuals in a team. It makes them work towards a common goal. Ubuntu according to Temples (1969) is a vital force. It is the soul of a team. It is the power that unites.

A project map illustrating the effects of ubuntu on cooperative learning is shown below.

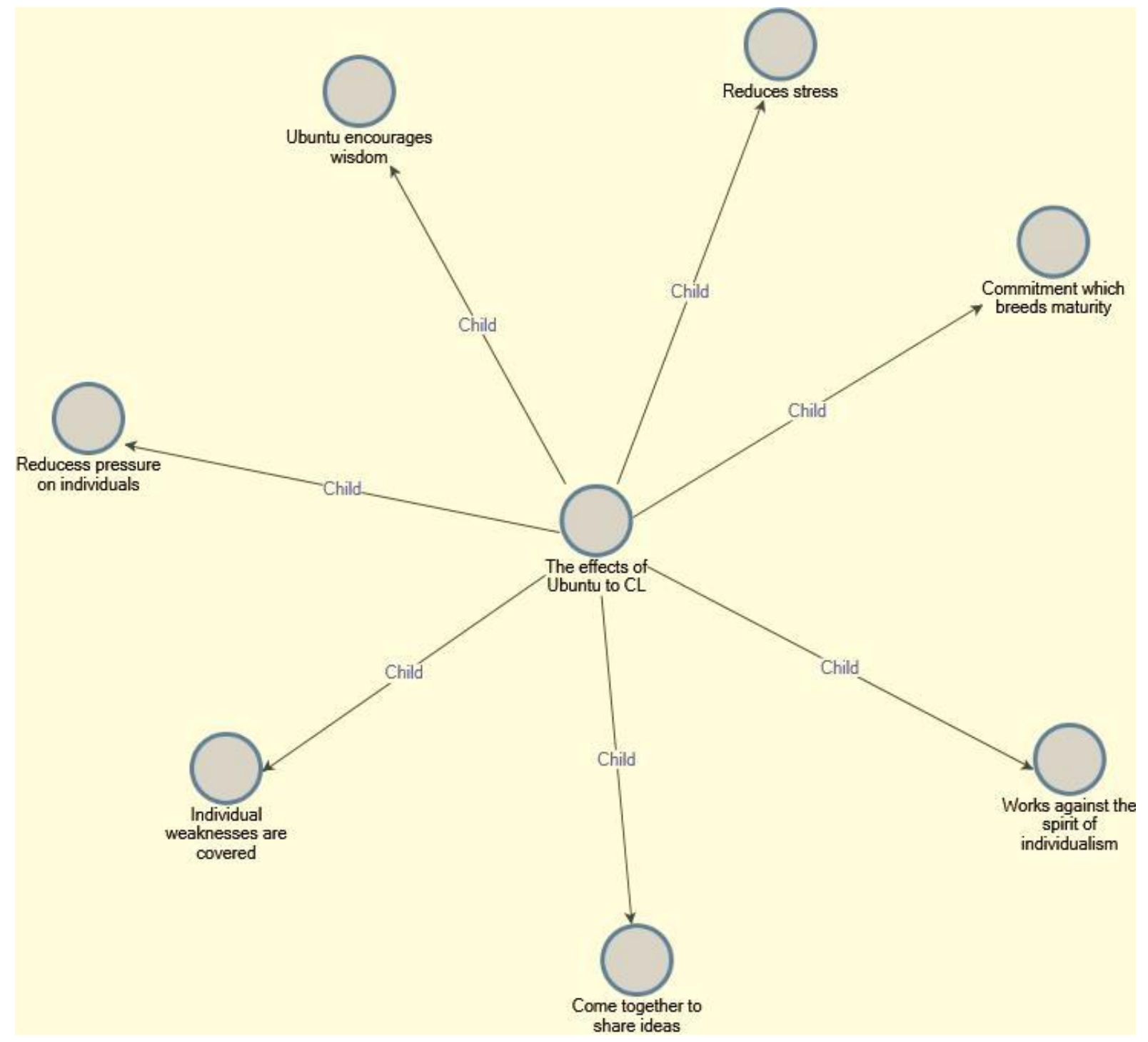

Figure 3. Field data showing the effects of ubuntu on cooperative learning 
Ubuntu works against the spirit of individualism, which improves learning. A community perspective is better than individualism in the sense that it is thorough and holistic; since ubuntu places an emphasis on the heart there is commitment and responsibility which breeds growth and maturity. Ubuntu encourages wisdom and cleverness instead of mere intelligence. Those governed by ubuntu are wise. Since ubuntu places an emphasis on emotions too there is a real presence of practical commitment and practical achievement. There is no speculation, people achieve reality. The whole is meant to be present through ubuntu.

Problems are solved at a macro level. We identify problems as a group and solve them as a group, which reduces stress and pressure on the individual because a problem shared is a problem solved. Individual weaknesses are covered. We know we all have individual weaknesses, but when they are shared at a group level they are converted into positive actions. Also, through CL, people are able to discover new things at a faster rate. Remember when we are three or four there is no way each one of us can be aware of what is happening. Let's say there is an issue to be done, the moment we give each other a task to go and make an investigation on how to deal with the problem we are going to attack that problem from different angles. So when we come together to share these things you discover that there are certain issues you were not aware of, so you discover those things at a faster rate than when you were to wait or to work on the problem on your own. There are some hidden things that we are not able to discover on our own. Yes, we may discover some things, but it's about the time factor because you cover a lot of ground within a short space of time through CL as different tasks are assigned to different people. So in terms of syllabus coverage in teaching and learning a lot of work is covered within a short time giving students ample time to revise, so it works to the advantage of the teacher and students. The teacher covers the syllabus within a short space of time and also students cover a lot of ground within a short space of time.

One of the negative effects of ubuntu in Africa is that it is not yet realized as a philosophy but it is still a culture. As a result there is no thorough commitment of the mind. As a culture, ubuntu is not trusted and it is weak because it is relative. It promotes both good and bad actions. It promotes laziness. It promotes disunity, for example 'mutorwa ngaaurawe' (the foreigner must be killed). Once it is realized that we are not from the same community, ubuntu culturally can be used as a reason for enmity and fighting. It promotes docility; weaker students or even introverts may be shy to participate for a number of reasons. One reason may be a language barrier; if teaching and learning is conducted in a language that is not user friendly for some students they may fail to express themselves and in the end they may lose out. It becomes teaching and learning for the gifted ones. Also it may promote laziness on the part of the teacher; instead of making a vigorous critical search for information to be taught or shared with the students the teacher may end up assigning students whilst he engages in other activities knowing that students will do something. It may work in two ways, it can be an advantage or a disadvantage. A lazy teacher may simply rely on the feedback from the students, that is the disadvantage. So if those students produce or give poisonous information it means the whole class is going to feed on absolute information and there is a source of lack of depth in critical approaches to issues if the teacher is lazy.

A search for ubuntu is critical in teaching and learning in the sense that there is enlightenment on the shortfalls of the Western individualistic learning method. There is also full realization of how indispensable ubuntu is in learning. Ubuntu is a better learning tool since it is inherent, traditional and original to Africans. The Western methods are foreign and isolated. Africans have to have their own philosophy of learning. Challenges and issues that arise in the context of learning call for or demand a homegrown solution which is ubuntu. It is an injustice to place in the hands of an African child a foreign philosophy to solve their problems. An African child cannot use the borrowed personality to solve their own problems. They need to discover their own identity, dignity and freedom and they cannot achieve this without ubuntu.

Since teaching and learning involve conducting the less educated into the province of knowledge, there are some moral intricacies or problems that may interfere with and impede teaching and learning because of cultural differences, as not all cultures are perfect. So in teaching ubuntu we are trying to find the common denominator within a diversified community that we think citizens or learners can benefit from, because our classes are heterogeneous and not homogeneous. So by teaching ubuntu we promote a culture of tolerance and knowledge of that which is more critical for the survival of humanity. Also it is because of ubuntu that societies are able to survive or to collapse. Remember we live in a global village where information is just flooding society, but not everything coming from the global world is constructive, for example, internet access. Looking at the age of students internet does not sieve or select what ought to be known or to be learnt by students. So some of the things that we think are good, if they go unchecked and not guided by what constitutes ubuntu, may end up developing citizens and students who are morally decadent. We talk of educated fools; people with qualifications but even with their qualifications make foolish decisions, for example after completing university you hear the student has HIV/AIDS. You spend a lot 
of time learning only to finish when one is HIV positive. There is no link between academic achievement and moral development, so in ubuntu we say whilst we respect an individual's intellectual development, your intellectual development must be guided by moral contact. You must be concerned about yourself and others. So with globalisation or these floodgates of knowledge, not everything being paraded as knowledge is knowledge per se, some is detrimental because of age and environment.

Critical analysis is showing that ubuntu is not an issue that is tribal or ethnic, it refers to every person in his or her own capacity. That's why in Zimbabwe the government opened up its approach to ubuntu by admitting that local languages must be taught and examined. And even universities in Zimbabwe are making efforts to introduce minority programmes like chiVenda and Nambia and translating these vernacular languages into constitution to shed light that these people are equally as important as the dominant groups. It was through CL that we realised we are excluding other people. From an understanding of ubuntu or Zimbabwean community tiri vanhu (we are all human), but being people we are different in that some are dialectically well pronounced. Some are considered as minority. Yet in ubuntu we don't have the minor and the major, we are the same, that's why we have these moves.

There is an urgent need to complement the Western methods of learning which are distractively individualistic in nature. Africans are by nature community-oriented not individual-oriented, and their learning methods must comply with their nature, failing which there is no learning or there will be total distraction. It makes African children become foreigners in their own schools and institutions of learning. So there is need to rejuvenate ubuntu.

Ubuntu is critical in the sense that it provides the framework of human behaviour within and outside the school society. Remember, John Dewey said that the school is a miniature society; what happens in schools is a reflection of what happens in the broader society. By teaching ubuntu in schools we are preparing our learners to become responsible members of the bigger society. So ubuntu is critical in the sense that either we build or we destroy our future. By teaching ubuntu we are acknowledging that humanity cannot just be a collection of individuals who operate haphazardly. Ubuntu is also critical in the sense that it accepts the universality of humanity. This means human beings, wherever they are, are bound to receive all the respect and dignity that is embebbed in every person despite differences in colour, class or political affiliation. Ubuntu perspective is to consider the humanness of the person which is not the appearance but the moral aspect of the self. That's why, be it a Western community or African community, there is no community which promotes stealing and killing. Every community is against those things but it is how it is taught that differs, so by exposing citizens or students to ubuntu we are admitting that humanity is one. It is a way of promoting respect and love for each other as persons, that's why ubuntu is critical. So through CL we learn to develop the habit of respecting office bearers, which is part of the African culture of gerontocracy as these leaders are mini adults.

In addressing the question that sought to find out some of the manifestations or signs of ubuntu in CL, one participant indicated that ubuntu is manifested in the new curriculum where pupils are supposed to play pada and nhodo (games traditionally played by African children). It also teaches traditional dance which is part of ubuntu. We are beginning to influence the effects in the new curriculum, where the students are encouraged to work together through group discussion and playing games as a way of encouraging team work. The best united team wins. Students are encouraged to love one another.

In CL we have issues like allocating of responsibilities where individuals may be asked to be group leaders or to talk after being granted the platform. It is part of ubuntu that we respect every person with a responsibility in a community as leaders. We do not exist haphazardously, there is order. So through CL we are trying to create an orderly society where we work according to assigned duties. I think it is part of ubuntu that we have different responsibilities and we have to be responsible.

\section{Discussion of Findings}

Findings revealed that ubuntu refers to the elements of humanness and humanity. In support, Higgs (2003:13) argues that the underlying concern of 'ubuntu' acknowledges that to be humane is to affirm one's humanity by recognising the humanity of others. Through ubuntu students have an obligation to reason, truth telling, hospitality, humility and dignity. Humanity is perpetuated as the students learn to respect others. Johnson (2015:4) is of the view that, the nature and character of CL essentially calls for ubuntu as its foundation since CL promotes non-racialism, non-sexism, non-discrimination, respect for freedom, human rights promotion and dignity of people, inter-dependence and the deep-rootedness of a collective community. Non-racialism is observed as students from diverse cultures are housed under one roof as they are learning. For instance students from other countries have been enrolled to learn with the local ones. CL is promoted as they are sharing ideas. They tend to learn some expectations from the different cultures. 
Prominent to ubuntu is the way people relate in a community. An individual is a community; a component found in ubuntu philosophy that is typically African. "Munhu munhu navanhu, umuntu ngumuntu ngabantu", which means that a person is a person through other persons. We do it together and the end product does not belong to an individual but to us a group. Individuals should be open and available to others, and not feel threatened that others are able and good. Khoza (2005:266) described communalism as "a concept that views humanity in terms of collective existence and intersubjectivity, serving as the basis for supportiveness, cooperation, collaboration and solidarity". Through collaboration the students will know that they achieve or fail as a team. Thus students 'sink or swim together' where there is responsibility for each other and individual and group accountability (Hartman, 2010:161). In concurrence, Brame and Biel (2015:15) are of the opinion that students ought to understand that their group task is 'sink or swim', and that group success depends on the personal commitment of each member. Personal commitment has a bearing on the students' achievement as the performance of team members affects the whole group. They are affected to the extent that all members within a group are bound to be awarded the same mark. To some extent this may promote laziness as some students might not be contributing effectively knowing that all team members will get the same score.

Findings also revealed that the hub of ubuntu is love so it is from love that all other tenets of ubuntu radiate. Love is guaranteed through ubuntu mainstreaming in the education curricula, which ensures and guarantees peace, harmony, spirit of brotherhood, togetherness, respect, solidarity, teamwork, unity, reconciliation and hard work among other important values (Bondai \& Kaputa, 2016:40). Peace and harmony is achieved as the students learn to respect diverse views from their colleagues. By respecting other students unity is achieved within the learning circles. It was further outlined that without love, in an African sense one does not qualify to be a person. One of the interviewees indicated that CL may entail learning that involves team participation where individuals have a contribution towards the learning process and achievement of goals in teaching and learning. Ubuntu therefore aims to eliminate the spirit of individualism perpetuated through such teachings as, 'Ini ndini, iwe ndiwe' (I am, you are), which emphasize the individual separateness from other members of the community (Hapanyengwi-Chemhuru \& Makuvaza, 2014:3). It presupposes doing together or working together towards a common goal. The traditional Shona society is against those individuals who seek fulfilment outside the context of the group (Mandova \& Chingombe, 2013).

One of the participants indicated that in ubuntu we normally say 'I am because we are, since we are therefore I am.' 'Munhu vanhu' (A person is there because of other people) calls for interdependence and a realisation that individuals cannot exist alone but with and among others. So cooperation becomes crucial for the survival of the community. Ubuntu helps to develop the spirit of sharing and caring for others. One is supposed to be tolerant because they are in a group of other people, so one lowers down their identity so that they fit in the group.

Findings also revealed that ubuntu makes team members work towards a common goal. As students work cooperatively they gain from each other's efforts; they share a common fate and feel proud for group success (Akhtar, Perveen, Kiran, Rashid \& Satti, 2012:142). Ubuntu works against the spirit of individualism, which improves learning. Ubuntu therefore aims to eliminate the spirit of individualism perpetuated through such teachings as, 'Ini ndini, Iwe ndiwe' (I am, you are), which emphasize the individual separateness from others. Hence Mandova and Chingombe (2013:101) observed and identified ubuntu as the better tool in order to promote cooperative learning, and they argue that the traditional Shona society celebrates co-operation and discourages individualism. Masowa and Mamvura (2017:34) submit that ubuntu values togetherness and oneness and shuns individualism as reflected in the following Shona proverbs:

\section{Kuchera mbeva kukomberana (Digging after mice involves surrounding them).}

Kuturika denga remba kubatirana (To put a roof onto the walls of a hut requires joining hands).

Chisaka, Chiome, Dambudzo and Mapolisa (2015) reiterated that ubuntu/hunhu philosophy would not support individualism, or achieving at the next person's expense, because working against other people's interests or disadvantaging them in any way "hazvina hunhu" in Chishona (which means that behaviour lacks humane-ness or empathetic feeling). In the ubuntu/hunhu philosophy there is more than just the egalitarian value - there is the value of empathy and humane-ness.

Further views suggest that ubuntu promotes and boosts self-confidence and self-esteem among the learners. It also enables members concerned to develop the spirit of sharing and caring for others. By teaching ubuntu in schools we are preparing our learners to become responsible members of the bigger society. In support of the above view, Mthiyane (2014:140) suggests that getting learners to become actively engaged and responsible for their own learning in a class community enhances creativity and innovativeness in the culture of learning. There is a spirit of communalism, 'rume rimwe harikombe churu' (one man cannot surround an anthill). In support of communalism, 
Ramose (2002) believes that interdependence, collective consciousness and a communalist worldview are of the utmost importance in the African way of life.

Hence without ubuntu there is irrationality, chaos, disorder, selfishness and separation; everything is scattered. Ubuntu makes learning itself affordable and easy, since there is interdependence, in the sense that what is difficult for one is easy for the other. It may however promote docility as weaker students or introverts who may be shy to participate for a number of reasons may become lazy. It also promotes disunity, for example it is said 'mutorwa ngaaurawe' (the foreigner must be killed). Once it is realized that we are not from the same community, ubuntu culturally can be used as a reason for enmity and fighting.

\section{Proposed Theory}

As the grounded theory emphasises the generation of a new theory, a communalist enhanced theory was adopted. Communalist enhanced learning anchors on social interdependence which promotes task, behavioural and goal interdependence. The figure below illustrates the communalist enhanced learning theory.

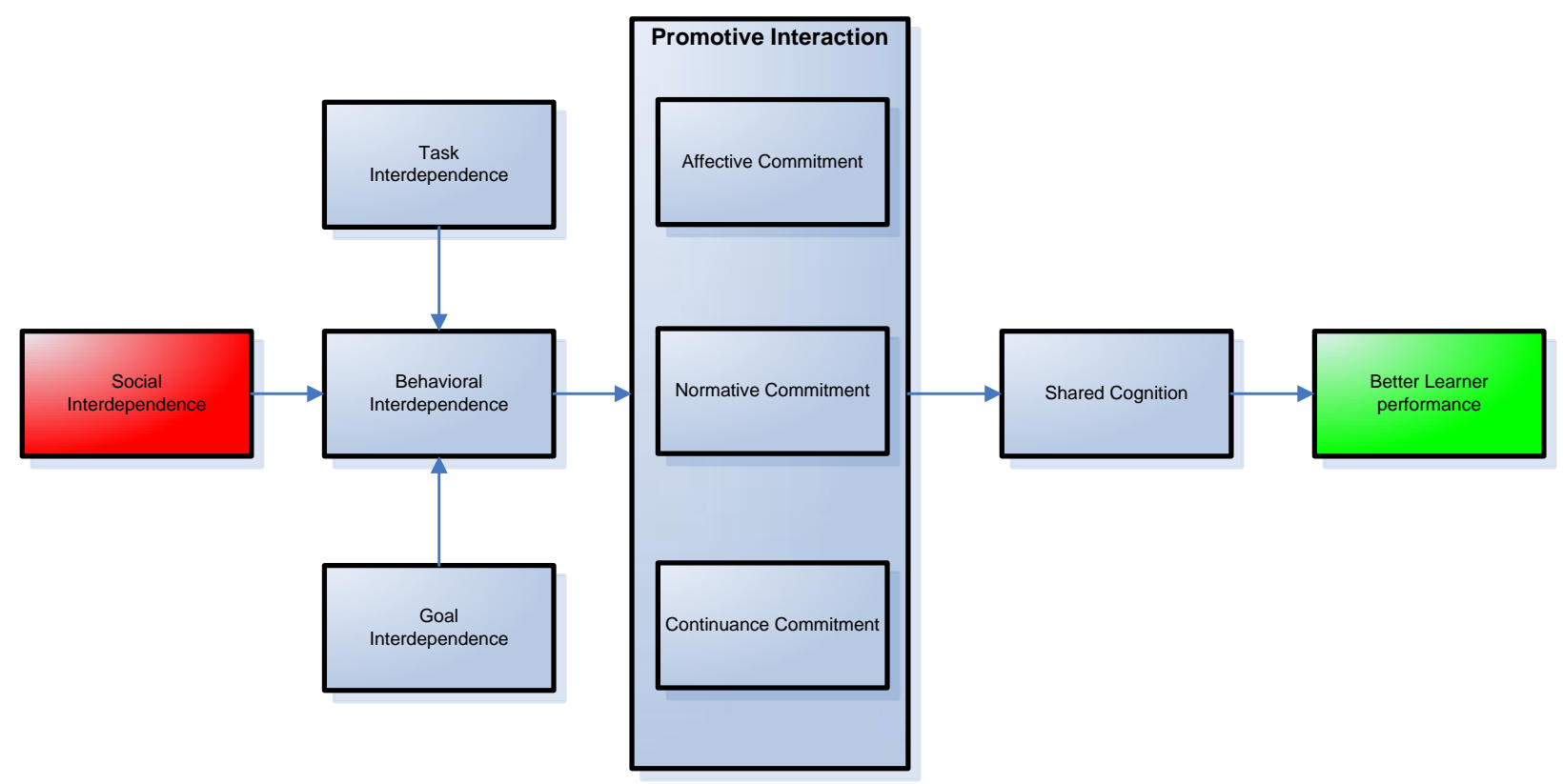

Figure 4. Communalist enhanced learning

Given the fundamental role of curriculum change in facilitating excellence in education, the researcher proposes a communalist enhanced learning theory. This supports the provision of tutoring that is appropriate to the general CL of students. As students come from diverse backgrounds, $21^{\text {st }}$ century learning proposes the necessity for learning methods that are communalist enhanced. The emphasis on communalism in an African thought and experience requires education to pay attention to interpersonal and cooperative skills (Higgs, 2003:15). From a communalist enhanced learning approach, teaching outlines the teachers' need to recognise and appreciate their students' various principles and societies. Learning thus involves the mindful and effortful involvement of students in the individual and social processes of knowledge and skills acquisition through interaction with the environment (Alberta Education, 2016:4). This allows children to develop positive attitudes towards people from other cultures (Tarman \& Tarman, 2011:580). Positive attitude is developed through social interdependence.

Through goal interdependence, learners strive to achieve the goals by depending on their colleagues. Accordingly, each member of a team is responsible not only for learning what is taught but also for helping team mates learn, thus creating an atmosphere of achievement (Tsay \& Brady, 2010:2). Behavioural interdependence denotes the communal influence which individuals have collectively interlinked in their existence and their day-to-day events. Interdependence remains indispensable as people cannot live in isolation. An individual therefore seeks an outcome that is beneficial to the self and others with whom the person is cooperatively linked (Johnson \& Johnson, 2014:841). 
This facilitates task interdependence which is the degree to which a task involves the collaboration of all team members. Task interdependence demands considerable cooperation among group members to accomplish activities (Bachrach, Powell, Collins \& Richey, 2006:1397). Individuals easily reach a consensus when dealing with the tasks allocated to them as they work as a team. Team members work with a sense of interdependence, as well as share expertise and responsibility for the execution of a given task (D'Silva, Ortegal \& Sulaiman, 2016:96). Their obligation is to work towards a collective aim to attain the assigned task. Ubuntu/hunhu philosophy should ensure that it promotes equitable learning prospects for the accomplishment of all learners' interests and abilities.

\section{References}

Akhtar, K., Perveen, Q., Kiran, S., Rashid, M., \& Satti, A.K. (2012). A study of student's attitudes towards CL. International Journal of Humanities and Social Sciences, 2(11), 141-147.

Alberta Education. (2016). The guiding framework for the design and development of kindergarten to grade 12 provincial curriculum (Programs of study). Edmonton: Crown in Right of Alberta.

Babbie, E. (2007). Paradigms, theory and social research in the practice of social research (11th ed.). California: Thomson Wadsworth.

Bachrach, D.G., Powell, B.C., Collin, B.J., \& Richey, R.G. (2006). Effects of task interdependence on the relationship between helping behaviour and group performance. Journal of Applied Psychology, 91(6), 1396-1345. https://doi.org/10.1037/0021-9010.91.6.1396

Belmekki, A., \& Kebiri, A. (2014). Co-operative learning in EFL classes: A students' grammar competence enhancement process. European Journal of Research and Reflection in Educational Sciences, 2(3),

Bitzer, E. (2001). Cooperative learning: A case study in tracing relationships to social constructivism and South African socio-educational thought. SAJHE/SATHO, 2(15), 98-104. https://doi.org/10.4314/sajhe.v15i2.25360

Blance, T., Durrheim, M., \& Painter, D. (2006). Research in practice: Applied methods for the social sciences (2nd ed.). Cape Town: UCT Press.

Bondai, B., \& Kaputa, T.M. (2016). Reaffirming Ubuntu/Unhu mainstreaming in the education curricula: Panacea for sustainable educational change in Southern Africa. International Journal of Academic Research and Reflection, 6(4), 37-44.

Brame, C.J., \& Biel, R. (2005). Setting up and facilitating group work: Using cooperative learning groups effectively. Retrieved May 20, 2018, from http://cft.vanderbilt.edu/guides-sub-pages/setting-up-and-facilitating-group-work-using-cooperative-learning-gr oups-effectively/

Chadha, A. (2013). Special education: Helping children with attention problems. New Delhi: APH Publishing Corporation.

Chisaka, B., Chiome, C., Dambudzo, I., \& Mapolisa, T. (2015). Analysis: Bringing Ubuntu to Zimbabwe education. The Sunday Mail, 15 March.

Cohen, L., Manion, L., \& Morrison, K. (2000). Research methods in education. New York: Routledge Falmer.

D’Silva, J.L., Ortegal, A., \& Sulaiman, A.H. (2016). Influence of personal and task interdependence on task conflict and team effectiveness. Modern Applied Science, 10(4), 94-100. https://doi.org/10.5539/mas.v10n4p95

Dawson, C. (2002). Practical research methods: A user-friendly guide to mastering research techniques and projects. Oxford: United Kingdom Cromwell Press.

Dawson, C. (2007). A Practical Guide to Research Methods, A User Friendly Manual for Mastering Research Techniques and Projects (3rd ed.). How to Books Ltd., Oxfordshire.

Fischer, C.T. (2006). Qualitative research methods for psychologists: Introduction through empirical studies. United States of America: Elseveir Book Aid International.

Flick, U. (2014). Introducing research methodology. Los Angeles: SAGE Publications Inc.

Gubbad, A.B.M.A. (2010). The effect of cooperative learning on the academic achievement and retention of the mathematics concepts at primary level in Holy Makkah. Edu. Sci \& Islamic Studies, 22(2), 13-23.

Hapanyengwi-Chemhuru, O., \& Makuvaza, N. (2014). In search of an indigenous philosophy for the Zimbabwean education. Journal of Indigenous Social Development, 3(1), 1-15. 
Hartman, H.J. (2010). A guide to reflective practice for new and experienced teachers: The practical guide series. New York: McGraw Hill.

Hennick, M., Hutter, I., \& Bailey, A. (2011). Qualitative research paradigm. London: Sage Publications Ltd.

Higgs, P. (2003). African philosophy and the transformation of educational discourse in South Africa. Journal of Education, (30), 5-22.

Iyer, R.B. (2013). Relation between CL and student achievement. International Journal of Education and Information Studies, 3(1), 21-25.

Johnson, D.W., Roger, T., \& Johnson, R.T. (2014). Cooperative learning in 21st century. Anales de Psicología, 30(3), 841-851. https://doi.org/10.6018/analesps.30.3.201241

Johnson, L.R. (2015). The African philosophy of "ubuntu" and correctional education in South Africa: A case study. Proceedings of the $38^{\text {th }}$ AFSAAP Conference: 21st Century Tensions and Transformation in Africa, Deakin University, and 28th-30th October 2015. African Studies Association of Australasia and the Pacific (AFSAAP).

Kothari, C.R., \& Garg, G. (2014). Research methodology: Methods and techniques. New Delhi: NewAge International (P) Limited.

Kufakunesu, M., \& Dekeza, C. (2017). Symbiosis during examination preparation: The perceived utility of group discussions to university students in Zimbabwe. Educational Research International Journal, 6(1), 50-62.

Letseka, M.M. (2014). Understanding of African philosophy through philosophy for the children (P4C). Mediterranean Journal of Social Sciences, 4(14), 348-355. https://doi.org/10.5901/mjss.2013.v4n14p745

Letseka, M.M., \& Venter, E. (2012). How student teachers understand African philosophy. Koers - Bulletin for Christian Scholarship, 77(1), 25. https://doi.org/10.4102/koers.v77i1.25

Mack, L. (2010). The philosophical underpinnings of educational research. Polyglossia, 19, 5-11.

Mandova, E., \& Chingombe, A. (2013). The Shona proverb as an expression of unhu/ubuntu. International Journal of Academic Research in Progressive Education and Development, 2(1), 100-108. https://doi.org/10.1163/9789401209151_022

Mangena, F. (2012). Towards a hunhu/ubuntu dialogical moral theory. Phronimon, 13(2), 1-17.

Masowa, A., \& Mamvura, Z. (2017). African philosophy of development as expressed in Shona proverbs. International Journal of Arts and Humanities (IJAH), 6(2), 28-40. https://doi.org/10.4314/ijah.v6i2.3

Metz, T. (2011). Ubuntu as a moral theory and human rights in South Africa. African Human Rights Law Journal, (11), 532-560.

Msila, V. (2009). Africanisation of education and the search for relevance and context. Educational Research and Review, 4(6), 310-315.

Mthiyane, N. (2014). CL as an innovative strategy in the teaching of life orientation education: Experiences of PGCE pre-service students. Alternation, 21(1), 137-152.

Nicolson, R. (2008). Persons in community: African ethics in a global culture. Pietetmaritzburg: University of Kwazulu Natal.

Petty, G. (2006). Evidence based teaching: A practical approach. London: Nelson Thornes Ltd.

Pujari, V., \& Rao, D. S (2013). Encouraging co-operative learning. Journal of Business Administration and Education, 2(1), 21-34.

Ramose, M. B (2002). The philosophy of ubuntu as a philosophy. In P. H. Coetzee \& A. P. J. Roux (Eds.), Philosophy from Africa: a text with readings. Oxford University Press.

Samkange, S., \& Samkange, T.M. (1980). Hunhuism or ubuntuism: A Zimbabwean indigenous political philosophy. Harare: Graham Publishing.

Somekh, B., \& Lewin, C. (2005). Research methods in the social sciences. London: SAGE Publications.

Tarman, B., \& Tarman, I. (2011). Developing effective multicultural practices: A case study of exploring a teacher's understanding and practices. The Journal of International Social, 4(1), 578-598.

Tavakoli, H. (2012). A dictionary of research methodology and statistics in applied linguistics. Tehran: Rahnama Press. 
Tracy, S.J. (2013). Qualitative research methods: Collecting evidence, crafting analysis, communicating impact. Oxford: John Wiley \& Sons Ltd Publication.

Tsay, M., \& Brady, M. (2010). A case study of cooperative learning and communication pedagogy: Does working in teams make a difference?. Journal of the Scholarship of Teaching and Learning, 10(2), 78-89.

Venter, E. (2004). The notion of Ubuntu and communication in Africa educational disclosure. Studies in Philosophy and Education, 23, 149-160. https://doi.org/10.1023/B:SPED.0000024428.29295.03

Vijayan, V., Shahrill, M., Abbas, N.A., \& Tan, A. (2016). Exploring the graphs of functions using the jigsaw approach. The Eurasia Proceedings of Educational \& Social Sciences (EPESS). 4, 399-408.

Yin, R.K. (2009). Case study research: Design and methods (2nd ed.). New Delhi: International Educational and Professional Publisher.

Yin, R.K. (2011). Case study research: Design and methods (7th ed.). New Delhi: SAGE Publication. 